\title{
AN EVALUATION OF EMPATHY WITHIN A PSYCHIATRY RESIDENCY TRAINING PROGRAM IN MACEDONIA
}

\author{
Miloš Milutinović1, Emilija Spasić ${ }^{1}$, Suada Elezi', James N. Kimball² \\ 1- University Clinic of Psychiatry - Skopje, Macedonia \\ 2 -Wake Forest School of Medicine, Department of Psychiatry and Behavioral Medicine, Winston-Salem, NC, USA
}

\section{INTRODUCTION}

Despite evidence for the centrality of the doctor-patient relationship in effective psychiatric treatment, ${ }^{1-4}$ the current research paradigm of psychiatry has paid limited attention to the role of empathetic human understanding in routine psychiatric treatment, including in terms of effective methods or techniques for working empathetically with psychiatric patients in routine practice. ${ }^{1,5-7}$ Psychiatry has faced significant criticism in the lay media ${ }^{8}$ and psychiatric literature ${ }^{1,5}$ for over relying on the Diagnostic and Statistical Manual of Mental Disorders (DSM) and medications while disregarding empathetic, humanistic interventions. ${ }^{1,6,7}$ Helping those with mental illness involves use of empathetic skills throughout practice, including in situations where mental health disorders directly interfere with individuals' willingness to seek help, their ability to form trusting relationships or their ability to communicate with others logically and emotionally. In spite of the evidence for the importance of these empathetic interpersonal aspects of psychiatric treatment, there has been little recent discourse in the psychiatric literature about how empathy can be effectively used in the day-to-day practice of clinical psychiatry. ${ }^{8}$

The Helpful Responses Questionnaire (HRQ) is designed to measure the development of reflective listening and empathy skills. These skills are central to the implementation of motivational interviewing in mental health, addiction, and social service settings. ${ }^{9}$ While there are other validated empathy questionnaires in the literature, the $\mathrm{HRQ}$ is unique in that the respondent has to write freeform answers as opposed to answering on a Likert scale.

The current study is designed to evaluate empathy in psychiatry residents in Macedonia.

\section{METHODS}

Psychiatry residents at the University Clinic in Skopje, Macedonia were surveyed in the Macedonian language. The Helpful Responses

Questionnaire was translated into the Macedonian language by English proficient psychiatric residents, and then the responses were translated back into English by the same residents. Responses were evaluated by an English speaking physician and a Macedonian physician. Ratings were assessed using a 5 point ordinal scale referencing "Thomas Gordon's Twelve Roadblocks."

\section{RESULTS}

21 out of 23 residents responded to the questionnaire. Results to each question were as follows:

\section{Helpful Responses Questionnaire}

1. A 41 year old woman says to you: "Last night Joe got really drunk and he came home late and we had a big fight. He yelled at me and I yelled back and then he hit me really hard! He broke

a window and the TV set, too! It was like he was crazy. I just don't know what to do!"

2. A 36 year old man tells you: "My neighbor is really a pain. He's always over here bothering us or borrowing things that he never returns. Sometimes he calls us late at night after we've gone to bed and I really feel like telling him to get lost."

3. A 15 year-old girl tells you: "I'm really mixed up. A lot of my friends, they stay out really late and do things their parents don't know about. They always want me to come along and I don't want them to think I'm weird or something, but I don't know what would happen if I went along either."

4. A 35 year old parent says: "My Maria is a good girl. She's never been in trouble, but I worry about her. Lately she wants to stay out later and later and sometimes I don't know where she is. She just had her ears pierced without asking me! And some of the friends she brings home - well l've told her again and again to stay away from that kind. They're no good for her, but she won't listen."

5. A 43 year old man says: "I really feel awful. Last night I got drunk again and I don't remember what I did. This morning I found out that the screen of the television is busted and I think I probably did it, but my wife isn't talking to me. I don't think I'm an alcoholic, you know, because I can go for weeks without drinking. But this has got to change."

6. A 59 year old unemployed teacher tells you: "My life doesn't seem worth living any more. I'm a lousy father. I can't get a job. Nothing good ever happens to me. Everything I try to do turns rotten. Sometimes I wonder whether it's worth it."

\section{CONCLUSIONS}

Regardless of year of training, the rating of empathy using the Helpful Responses Questionnaire was severely lacking. It should be noted that the $H R Q$ is not validated against any treatment outcome. Although participants may improve motivational interviewing skills and empathic listening, improvement in score has not been associated with patient outcomes, (behavior change, medication adherence etc.) This would be a suggestion for future research with this tool. In addition, specific training modalities would be useful in determining if empathy is increased among psychiatric residents in Macedonia.

1. Bracken P, Thomas P, Timimi S, Asen E, Behr G, Beuster C, et al. Psychiatry beyond the current paradigm. Br J Psychiatry 2012; 201: 430-4. 2. Johansson H, Eklund M. Patients' opinion on what constitutes good psychiatric care. Scand J Caring Sci 2003; 17: 339-46.

3. Frank AF, Gunderson JG. The role of the therapeutic alliance in the treatment of schizophrenia: relation to course and outcome. Arch Gen Psychiatry 1990; $47: 228-36$. 4. Johansson H, Jansson J. Therapeutic alliance and outcome in routine psychiatric outpatient treatment: patient factors and outcome. Psychol Psychother 2010; 83 : 193-206.

5. Kleinman A. Rebalancing academic psychiatry: why it needs to happen - and soon. Br J Psychiatry 2012; 201: 421-2.

6. Baldessarini RJ. The impact of psychopharmacology on contemporary psychiatry. Can J Psychiatry 2014; 59: 401-5. 7. Joober R. Deconstructing the mental health crisis in only 2 pieces. J Psychiatry Neurosci $2016 ; 41: 222-4$

8. Ross J, Watling C. Use of empathy in psychiatric practice: constructivist grounded theory study. BJPsych Open. 2017 Feb 9;3(1):26-33. 